\title{
中国及周边地区夏季中尺度对流系统分布及其 日变化特征
}

郑永光 ${ }^{\circledR}$, 陈畑 ${ }^{\circledR}$, 朱佩君 ${ }^{(2)}$

(1) 国家气象中心, 北京 100081 ;

(2) 浙江大学地球科学系, 杭州 310027

E-mail: cjiong@cma.gov.cn

2007-10-08 收稿, 2007-12-13 接受

国家重点基础研究发展计划项目(批准号: 2004CB418300)和国家自然科学基金项目(批准号: 40305004)资助

摘要 利用 1996 2006 年(无 2004 年) 10 年 6 8 月地球静止卫星高分辨率逐时红外亮 温(简称 TBB) 资料对夏季中国及周边地区的中尺度对流系统(简称 MCS)活动情况进行了 统计分析, 并同已有文献中使用常规地面观测资料统计的雷暴日数分布以及低轨卫星观 测的闪电资料分析结果进行了对比, 结果表明低于 $-52^{\circ} \mathrm{C}$ 红外亮温的统计特征可以较好地 展现该地区夏季 MCS 时空分布的基本气候特征. 该地区夏季 MCS 的总体分布特点是具有 3 条东西分布的带状 MCS 活跃区; $30^{\circ} \mathrm{N}$ 附近的活跃中心表现为明显的东西波动状; 从大气 环流来看东亚夏季风把 3 条 MCS 活跃带联系在一起. 重点对不同下垫面区域的 MCS 日变 化特征进行分析表明中国及其周边地区具有单峰与多峰型两种 MCS 日变化特点, 单峰型 MCS 多发生在高原与山区, 多峰型 MCS 多发生于平原与盆地. 由于不同地区单峰型 MCS 持续时间与活跃时段的并不相同, 因此又可以区分为青藏高原 MCS、一般山地热对流、琉 球附近海域 MCS 等. 多峰型 MCS 具有类似于 MCC (中尺度对流复合体)日变化的特点, 反 映此类 MCS 生命史较长、水平尺度较大、日落后一度减弱、午夜后又再度发展. 青藏高 原 MCS 与一般山地热对流一般都在午后发展, 但青藏高原 MCS 持续时间长, $\mathrm{M}_{\alpha} \mathrm{CS}(\alpha$ 中尺 度对流系统)活跃. 琉球附近海域 MCS 具有午夜后发展、持续时间长的特点, $\mathrm{M}_{\alpha} \mathrm{CS}$ 也较活 跃. 印度季风涌地区由于充沛的水汽与有利的大尺度环境使得全天几乎任一时次 MCS 都 很活跃, 而且 $\mathrm{M}_{\alpha} \mathrm{CS}$ 非常活跃. 四川盆地地区由于山谷风环流的影响 MCS 夜发性特征特 别显著, 该区域也是 $\mathrm{M}_{\alpha} \mathrm{CS}$ 的活跃区之一. 两广地区海陆交界处是海陆风环流显著的区域, 因此 MCS 具有午后向陆地传播、午夜后向海洋传播的特征. 低于 $-52^{\circ} \mathrm{C}$ 红外亮温的气候统 计特征清楚地展现了海、陆、山地的热力性质差异所导致的 MCS 不同气候分布特点. 不 仅大尺度大气环流而且海、陆、山地热力差异引起的局地环流在很大程度上决定了中国及 周边地区夏季中尺度对流系统活动的气候特征.

关键词

中尺度对流系统 红外云图亮温

日变化 气候分布
夏季是强对流天气(如冰雱、雷雨大风等)频发的 季节. 产生强对流天气的天气系统主要是中尺度对 流系统(简称MCS), 由于MCS空间与时间尺度较小, 并常发生在傍晚与夜间, 因此地球静止卫星高时空 分辨率的红外云图与天气雷达是主要的监测手段.
使用长时间序列的常规气象观测资料也能获得陆地 区域的冰雹、雷暴分布 ${ }^{[1]}$, 但不能获得无常规气象观 测区域(如海洋等)的冰雱、雷暴分布. 此外, 使用常 规资料进行对流天气气候分析由于受到气象测站空 间分布以及日观测次数的影响, 也不能获得冰雱、雷 
暴等的高分辨率时空分布.

20 世纪 80 年代以来, 国内外利用静止卫星红外 云图资料对中国及周边地区开展了较多的MCS普查 工作, 取得了很多成果, 但都具有一定的局限性. Miller与Fritsch ${ }^{[2]}$ 对西太平洋的 $\mathrm{MCC}$ (中尺度对流复 合体，一种特殊的中尺度对流系统)进行了普查, 但 $\mathrm{MCC}$ 只占 MCS 的一小部分, 不能反映MCS分布的全 貌. 国内对MCS的普查大都是区域性的, 例如针对中

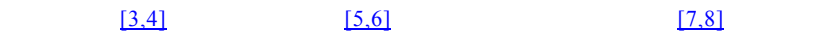
及周边地区 ${ }^{[9]}$ 、淮河流域 ${ }^{[10,11]}$ 等的MCS 普查. Ma等人 [12]对 1993 1995 年中国以及邻近区域的MCS进行了 较全面的普查分析, 但也只是针对椭圆率为 0.5 以上 的 $\mathrm{M}_{\alpha} \mathrm{CS}$ ( $\alpha$ 中尺度对流系统)与 1.5 纬度以上尺度的 $\mathrm{M}_{\beta} \mathrm{CS}$ ( $\beta$ 中尺度对流系统), 没有包括较小尺度的 $\mathrm{M}_{\beta} \mathrm{CS}$ 与形状较长的 PECS ${ }^{[13]}$ (Persistent Elongated Convective Systems, 持久的细长对流系统). 最近, 郑永光等人 ${ }^{[14]}$ 使用 1997 2004 年共 8 年的地球静止 卫星红外云图TBB(相当黑体亮度温度)资料对北京及 周边地区的深对流分布进行了时空分析, 获得了一 些新的认识; 该研究成果表明长时间序列 TBB资料 的对流统计结果更能客观、全面地代表对流天气的气 候特征, 并能够弥补使用地面观测资料与闪电观测 资料分析结果的不足 ${ }^{[14]}$.

闪电与MCS有非常密切的关系，因此可以使用 闪电资料对对流天气进行气候分析. 但目前国内的 地基闪电监测网尚未完全建成，马明等人 ${ }^{[15]}$ 、袁铁等 人 ${ }^{[16]}$ 分别使用 8 年低轨卫星观测的再分析 $0.5^{\circ} \times 0.5^{\circ}$ 闪电资料对中国及邻近地区的闪电时空分布进行了 分析研究, 其获得的闪电特征分布与常规观测资料 获得的雷暴分布 ${ }^{[1]}$ 具有较好的一致性, 但也在一些地 区存在较大差异, 比如青藏高原地区.

雷达资料具有很高的时空分辨率，具有监测强 对流天气的能力, 因此使用雷达资料进行对流天气 气候分析有很大的必要性. Jirak 等人 ${ }^{[17]}$ 综合使用卫 星与雷达资料对 1996 1998 年 4 8 月美国的MCS进 行了普查研究. 国内由于新一代天气雷达网正在建 设过程中, 目前还没有覆盖全国的较长时间序列的 反射率因子拼图产品用来进行MCS普查.

地球静止卫星数字红外云图资料可以反演为相 当黑体亮度温度(简称TBB), 虽然低TBB区有时仅反 映高云的特征, 不一定与强对流和强降水区相对应, 但TBB的数值大小通常可以定量地反映大气中对流
活动的强弱, 然而目前还没有使用长时间序列 TBB 资料较完整地普查中国及周边地区MCS的分布状况. 因此本文利用 10 年数字红外云图资料反演的TBB来 普查中国及周边地区夏季 $\mathrm{MCS}$ 的气候特征来弥补以 前相关研究的不足, 并同已有文献中根据常规资料 获得雷暴分布 ${ }^{[1]}$ 以及根据卫星资料获得的闪电分布 [15,16]进行对比, 以进一步充实对该区域MCS分布及 变化的气候规律认识.

\section{1 资料与方法}

本文所用地球静止卫星数字红外云图资料包括 北京大学物理学院大气科学系接收的日本 GMS-5 (Geostationary Meteorological Satellite 5, 第 5 代地球静 止气象卫星)与美国 GOES-9 (Geostationary Operational Environmental Satellite 9, 第 9 代地球静止业务环境 卫星)地球静止卫星以及国家卫星气象中心提供的中 国 FY-2C(风云二号 C 星)地球静止卫星的 TBB 资料. 北京大学提供的资料时间分辨率基本为 $1 \mathrm{~h}$ (部分时 次 $0.5 \mathrm{~h}$ 或者 $2 \mathrm{~h}$ 一次), 水平分辨率 $9.6 \mathrm{~km} \times 9.6 \mathrm{~km}$. FY-2C TBB 资料时间分辨率也基本为 $1 \mathrm{~h}$, 但水平分 辨率为 $0.1^{\circ} \times 0.1^{\circ}$. GMS-5 资料起止时间为 1996 年 5 月到 2003 年 5 月, GOES-9 资料为 2003 年 5 月到 2003 年 8 月, FY-2C TBB 资料的起止时间为 2005 年 6 月到 2006 年 8 月. 由于 2004 年北京大学 GOES-9 资料存 在较大的空间定位误差及较多缺测, 本文没有使用 该年的资料. 因此，本文使用的卫星资料是 1996 2006 年(无 2004 年)共 10 年 6 8 月的数字红外云图资 料, 其中 6 月的总时次数为 7033 时次, 7 月 7262 时次, 8 月 7021 时次, 6 8 月总共 21316 时次. 本文所称的 中国及周边地区是指东经 $80^{\circ} \sim 142^{\circ} \mathrm{E}$ 、北纬 $10^{\circ} \sim 55^{\circ} \mathrm{N}$ 的区域范围, 具体范围参见图 1(a)中的粗实线区域.

1980 年Maddox ${ }^{[18]}$ 提出使用 $-32^{\circ} \mathrm{C}$ 与 $-52^{\circ} \mathrm{C}$ TBB 标识的区域范围及形状等来识别 $\mathrm{MCC}$, Augustine和 Howard ${ }^{[19]}$, Jirak等人 ${ }^{[17]}$ 又提出只使用 $-52^{\circ} \mathrm{C}$ TBB来识 别MCS. 因此, 本文以每一网格点 $\mathrm{TBB} \leqslant-52^{\circ} \mathrm{C}$ 来识别 夏季大气中的 $\mathrm{MCS}$, 这样识别的MCS包含 $20 \mathrm{~km}$ 以上 尺度的 $\mathrm{M}_{\beta} \mathrm{CS}$ 与尺度较大的 $\mathrm{M}_{\alpha} \mathrm{CS}$, 从而比较全面地 普查中国及周边地区 $M C S$ 的空间分布与日变化特征. 此外, 选择 $\mathrm{TBB} \leqslant-52^{\circ} \mathrm{C}$ 来识别夏季大气中的 $\mathrm{MCS}$ 还 因为在对 2003 年淮河流域强降水与 $\mathrm{TBB}$ 关系的研究 中发现 $\mathrm{TBB} \leqslant-52^{\circ} \mathrm{C}$ 的 $\mathrm{MCS}$ 是导致淮河流域强降水的 重要天气系统 ${ }^{[11]}$, 因此本文对 $\mathrm{TBB} \leqslant-52^{\circ} \mathrm{C}$ 的 

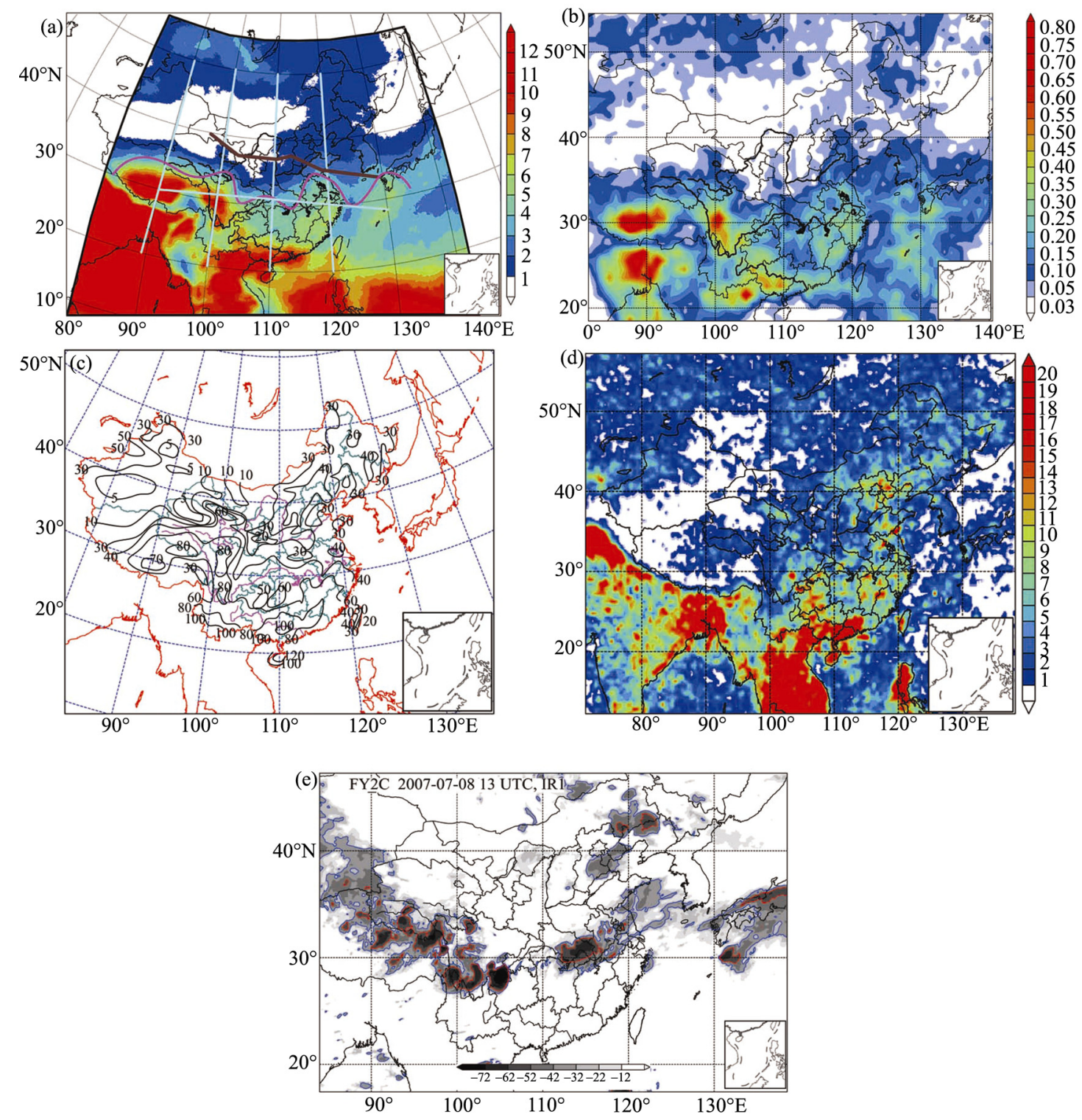

图 1 夏季MCS活动频率、平均年雷暴日分布 ${ }^{[1]}$ 与低轨卫星观测的闪电分布 ${ }^{[15,16]}$

(a) MCS分布(单位: \%, 淡蓝色实线为后文中MCS日变化剖面位置, 褐色实线为多年 7 月平均 $850 \mathrm{hPa} 340 \mathrm{~K}$ 假相当位温等值线的北端, 紫红色实线表示 $30^{\circ} \mathrm{N}$ 附近波动状对流分布); (b) $\mathrm{M}_{\alpha} \mathrm{CS}$ 活动频率(单位: \%); (c) 年平均雷暴日分布 ${ }^{[1]}$ (单位: d); (d) 低轨卫星观测的闪电 分布 ${ }^{[15.16]}$ (单位: 闪击数/年 $\cdot \mathrm{km}^{2}$ ); (e) 2007 年 7 月 8 日 13 UTC FY2C波状对流实例的TBB分布(其中蓝色和红色实线分别为 -32 与 $-52^{\circ} \mathrm{C}$ TBB 等值线)

MCS 统计在一定程度上能够代表江淮流域强降水的 气候分布特征, 但是其他地区特别是北方地区 TBB $\leqslant-52^{\circ} \mathrm{C}$ 与强降水关系还需要进一步的研究.

为了同 $\mathrm{Ma}$ 等人 ${ }^{[12]}$ 普查的 $\mathrm{M}_{\alpha} \mathrm{CS}$ 分布进行对比, 本文也给出了 $\mathrm{M}_{\alpha} \mathrm{CS}$ 的地理分布. 考虑到MCS包括圆 形MCS 与 $\mathrm{PECS}{ }^{[13]}$, 因此本文 $\mathrm{M}_{\alpha} \mathrm{CS}$ 定义为 $\mathrm{TBB} \leqslant$ $-52^{\circ} \mathrm{C}$ 的区域面积 $\geqslant 50000 \mathrm{~km}^{2[19]}$ 的MCS, 不定义形
状、生命史长短等其他因素. 不定义生命史长短的原 因是根据尺度分析的理论, 水平尺度大的MCS其时 间尺度也比较长 200 . 因此本文中的 $\mathrm{M}_{\alpha} \mathrm{CS}$ 是一个广义 定义.

在对 MCS 进行普查之前, 首先需要对卫星资料进 行预处理. 预处理过程包括滤除噪声、统一卫星资料水 平分辨率为 $9.6 \mathrm{~km} \times 9.6 \mathrm{~km}$, 统一数据格式等. 然后对 
10 年夏季每小时一次静止卫星 TBB 资料通过云图动画 的方法剔除有观测质量问题的资料(比如只覆盖半个中 国区域的云图, 地理定位有偏差的云图等).

本文 MCS 具体的统计方法为, 首先把整理好的 数字红外云图由灰度数值反演为 $\mathrm{TBB}$, 然后对统计 区域内各个网格点 $\mathrm{TBB} \leqslant-52^{\circ} \mathrm{C}$ 出现的时次分别进行 计数, 并剔除无效观测时次, 最后除以每一网格点所 有资料的总时次得到百分比, 从而获得中国及周边 地区整个区域 6 8 月 MCS 的日变化和地理分布特征.

统计 $\mathrm{M}_{\alpha} \mathrm{CS}$ 的方法是首先由计算机识别 $10 \mathrm{a}$ 夏 季每小时一次的 $\mathrm{M}_{\alpha} \mathrm{CS}$ 形心位置, 然后按照 $1^{\circ} \times 1^{\circ}$ 的 网格内的出现 $\mathrm{M}_{\alpha} \mathrm{CS}$ 形心时次数进行统计, 并把出现 $\mathrm{M}_{\alpha} \mathrm{CS}$ 形心的时次数除以该网格内资料的总观测时次 数, 最终获得中国及周边地区整个区域内 $1^{\circ} \times 1^{\circ}$ 水平 分辨率的 $\mathrm{M}_{\alpha} \mathrm{CS}$ 活动频率分布. 具体识别 $\mathrm{M}_{\alpha} \mathrm{CS}$ 的方 法是根据本文 $\mathrm{M}_{\alpha} \mathrm{CS}$ 的定义, 首先识别 $\mathrm{TBB}$ 为 $-52^{\circ} \mathrm{C}$ 的闭合边界线，如果该闭合区域内 $\mathrm{TBB} \leqslant-52^{\circ} \mathrm{C}$ 的面 积 $\geqslant 50000 \mathrm{~km}^{2}$ 则识别为一个 $\mathrm{M}_{\alpha} \mathrm{CS}$, 然后计算该 $\mathrm{M}_{\alpha} \mathrm{CS}$ 的形心位置.

\section{MCS 空间分布}

\subsection{MCS 总体分布}

图 1 给出了 $10 \mathrm{a}$ 夏季中国及周边地区MCS与 $\mathrm{M}_{\alpha} \mathrm{CS}$ 的总体分布特征以及已有文献中中国的年平均 雷暴日分布 ${ }^{[1]}$ 与低轨卫星观测的闪电分布 ${ }^{[15,16]}$. 图 1(a)中最显著的特征是MCS呈纬向带状分布, MCS主 要集中在该区域南部的热带与副热带地区, 并且在 $30^{\circ} \mathrm{N}$ 附近 MCS的大值中心呈现波状分布的特征(图 1(a)中的紫红色实线, 图 1(e)给出了 2007 年 7 月 8 日 $13 \mathrm{UTC}$ 一次典型波状对流分布的实例). 从南向北有 三条MCS活跃带，第一条MCS带位于北半球夏季热 带辐合带地区与印度季风涌区域, 包括菲律宾以东 的西北太平洋地区、菲律宾及其西侧的南海地区、中 南半岛地区、孟加拉湾及其北侧的喜马拉雅山脉的南 侧地区; 第二条MCS带从青藏高原地区向东延伸到 日本，除青藏高原等高原地区外的我国中东部地区 以及东海、日本等地区MCS的活跃区主要与东亚夏季 风以及梅雨锋相联系, 该条 MCS的活跃带主要包括 青藏高原的中东部地区、横断山区、川西高原、云南 南部、云南东北部、贵州西南部、广西、广东、长江 中下游地区、江西、福建、浙江以及琉球群岛附近海 域; 第三条MCS带位于 $50^{\circ} \mathrm{N}$ 附近, 是对流活动最弱
的MCS活跃带, MCS活跃区主要位于俄罗斯的叶尼 塞河源地萨彦岭到贝加尔湖一带, 并有两个对流中 心; 该条MCS带一般与中纬度地区的低槽活动相联 系, 地面观测有较多雷暴活动, 卫星观测有较多闪电 活动 ${ }^{[15,16]}$.

总体而言, MCS的这种分布形态与张家诚、林之 光 ${ }^{[1]}$ 获得的雷暴分布(图 1(c)) 以及马明等人 ${ }^{[15]}$ 、袁铁 等人 ${ }^{[16]}$ 获得的闪电分布(图 1(d))特征基本一致. 但值 得注意的是 8 年低轨卫星观测闪电分布显得比较零 散, 这可能与闪电在MCS中分布以及低轨卫星每天 的观测次数有关. 此外, 虽然青藏高原地区MCS活动

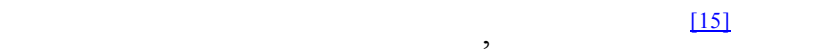
等人 16$]$ 获得的该地区闪电分布却比长江中下游地区 弱得多. 青藏高原MCS对应于较少的闪电分布可能 与高原上积雨云垂直厚度小、翻腾现象不强烈、云内 液态水含量少有关 ${ }^{[21]}$.

从 3 条MCS集中带的分布来看, 他们不是孤立的, 而是通过中低纬系统的相互作用连结在一起的. 热 带辐合带区域的MCS带通过夏季西南季风与我国南 方的MCS带、华北与东北地区的MCS多发区相联系. 特别突出的是广西、广东的MCS多发区与中南半岛的 MCS多发区联系在一起, 更清楚地显示出东亚夏季 风的作用. 图 1(a)中褐色实线为使用 2000 2006 年 7 年NCEP(National Center for Environmental Prediction, 美国环境预报中心) $1^{\circ} \times 1^{\circ}$ 分析资料平均获得 7 月份 $850 \mathrm{hPa} 340 \mathrm{~K}$ 假相当位温等值线的北端, 它代表了 西南季风的前沿. 在该线的南侧主要为热带季风气 团影响区域, 北侧为极地大陆气团或者变性气团与 热带季风气团交互影响区域 ${ }^{[22]}$; 从图 1(a)中可以清 楚地看到这条等值线的南侧区域热带季风气团内 MCS比北侧活跃.

图 1(a)也表明 MCS 分布不仅与纬度相关, 还与 地势分布、海陆分布密切相关. 北纬 $35^{\circ} \mathrm{N}$ 以南地区 的青藏高原、川西高原、云贵高原东北部、江西的罗 霄山区、福建的武夷山区、浙江与福建的闽浙丘陵都 是 MCS 的活跃区. 桂、粤地区的 MCS 活跃区除了与 东亚夏季风有关外, 还与两广丘陵、南岭、海陆分布 有关. 地势分布与海陆分布对 MCS 发生发展的影响 在第 4 部分的 MCS 日变化中有更清楚的展示.

马明等人 ${ }^{[15]}$ 通过全球的闪电分布发现琉球群岛 附近的黑潮主干海域是闪电的高发区, 他们认为黑 潮暖流的高温、高盐特征显著影响其流经海域强对流 
发展. 本文的结果也表明琉球群岛附近海域是一个 MCS 的高发区. 但从大气环流的来看该MCS活跃区 主要与夏季西南季风与北方弱冷空气活动造成的梅 雨锋以及北上台风活动有关 ${ }^{[23]}$.

MCS 不活跃区除了位于大陆腹地的中国西部的 盆地、沙漠地带以及蒙古国的沙漠地带, 还包括 $40^{\circ} \mathrm{N}$ 以北的日本海海域及其俄罗斯的沿海地区. 大陆腹 地 MCS 发生频率低主要与这些区域较难受到夏季西 南季风影响有关, 而 $40^{\circ} \mathrm{N}$ 以北的日本海海域及其俄 罗斯的沿海地区较少 MCS 发生可能与东亚夏季风较 难到达、该海域为冷洋流、海面温度较低有关.

图 1(b)给出的 $\mathrm{M}_{\alpha} \mathrm{CS}$ 分布表明中国及周边地区的 $\mathrm{M}_{\alpha} \mathrm{CS}$ 分布与总体的MCS分布非常类似, 但其活动频 率低于总体MCS频率两个数量级. $\mathrm{M}_{\alpha} \mathrm{CS}$ 的高发区为 青藏高原中部、横断山区、两广地区、长江中下游地 区、琉球群岛海域等. 同 $\mathrm{Ma}$ 等人 ${ }^{[12]}$ 的 $\mathrm{M}_{\alpha} \mathrm{CS}$ 普查结果 对比发现两者 $\mathrm{M}_{\alpha} \mathrm{CS}$ 多发区的分布基本一致, 但 $\mathrm{Ma}$ 等 人 ${ }^{[12]}$ 的普查结果青藏高原与横断山区的 $\mathrm{M}_{\alpha} \mathrm{CS}$ 明显少 于江淮地区与两广地区, 这与 $\mathrm{Ma}$ 等人 ${ }^{[12]} \mathrm{M}_{\alpha} \mathrm{CS}$ 的定 义比较严格有关. 另一个需要注意的是, 在海南岛周 边虽然有较多MCS分布, 但 $\mathrm{M}_{\alpha} \mathrm{CS}$ 分布却较少, 其原 因有待进一步研究.

\section{2 北方地区 MCS 的空间分布}

虽然北方地区MCS活动频率明显低于南方地区， 但郑永光等人 ${ }^{[14]}$ 对北京及周边地区的对流统计表明 该地区的北部以及东部地区是深对流的活跃区域, 因此我们在图 2 中给出了 $35^{\circ} \mathrm{N}$ 以北区域MCS的分布 情况. 图 2 表明MCS的最不活跃区域位于青海、新疆与 甘肃交界的戈壁、沙漠地带. 北方地区MCS最活跃的 区域位于北纬 $50^{\circ}$ 以北 $80^{\circ} \sim 110^{\circ} \mathrm{E}$ 的俄罗斯萨

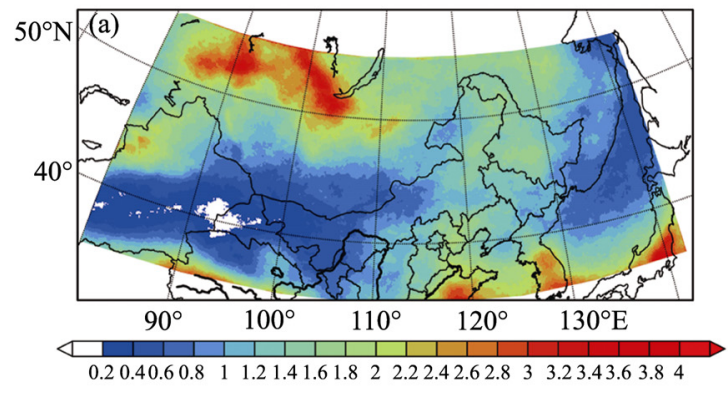

彦岭一带; 其次为渤海与黄海及其周边的朝鲜半岛 与山东半岛地区都有相当数量的MCS发生; 再次为 新疆自治区北疆的天山西部伊犁河谷到阿尔泰山一 带、北京及周边地区、内蒙古东部的大兴安岭与东北

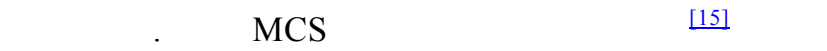

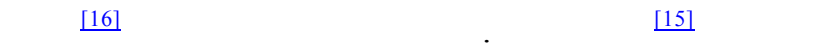
人 ${ }^{[16]}$ 分析这些闪电多发区与当地的地形分布有着密 切的关系. 从大气环流的气候背景来看, 这些MCS活 跃地区或者位于中纬度低槽的槽前或者位于夏季西 南暖湿气流的迎风坡一侧 ${ }^{[22]}$. 此外, 渤海与黄海及其 周边地区MCS活跃的原因可能还与海陆热力差异有 关.

值得一提的是, 在祁连山南簏的青海湖周边地 区也是一个MCS的活跃区，这也是一个 $\mathrm{M}_{\alpha} \mathrm{CS}$ 活跃区，

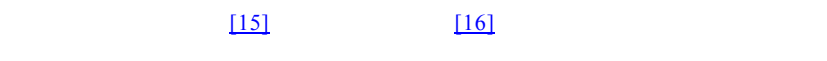
相一致. 从每日的云图演变也可以看到经常有对流 系统从该地区移出影响下游地区.

北方地区的 $\mathrm{M}_{\alpha} \mathrm{CS}$ 活跃区域也基本与MCS活跃区 域一致. 值得注意的是, 黄海与渤海及其周边地区都 有相当数量的 $\mathrm{M}_{\alpha} \mathrm{CS}$ 发生, 特别黄河下游地区以及朝 鲜半岛地区更是 $\mathrm{M}_{\alpha} \mathrm{CS}$ 的高发区域. 这与以前研究结 果 ${ }^{[7,8,12]}$ 相一致. 此外, 内蒙古东部的大兴安岭地区、 东北平原地区以及俄罗斯的外兴安岭地区也是北方 的 $\mathrm{M}_{\alpha} \mathrm{CS}$ 活跃区域.

\section{$3 \mathrm{MCS}$ 月变化特征}

图 3 表明 MCS 分布具有明显的月际变化特点, 不同地区 MCS 月变化特征不尽相同. 孟加拉湾及其 北侧的喜马拉雅山脉的南侧地区、中南半岛地区夏季 MCS 月变化不显著, 整个夏季 MCS 都很活跃. 菲律 宾以东的西太平洋地区、菲律宾及其西侧的南海地区

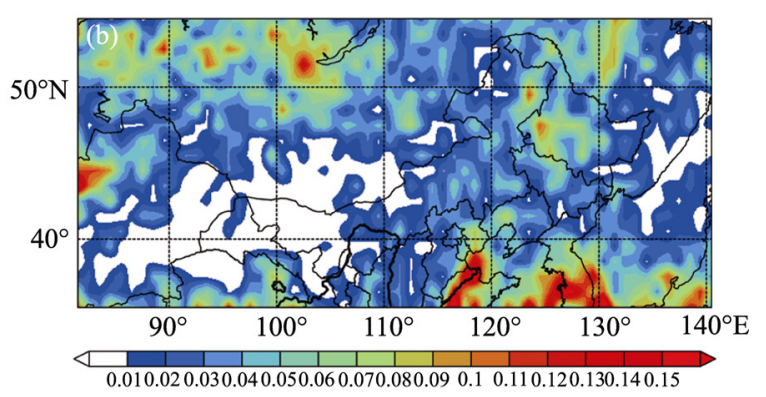

图 2 同图 1, 但为 $35 \sim 55^{\circ} \mathrm{N}$ 的 MCS 与 $\mathrm{M}_{\alpha} \mathrm{CS}$ 活动频率(单位: \%)

(a) MCS; (b) $\mathrm{M}_{\alpha} \mathrm{CS}$ 

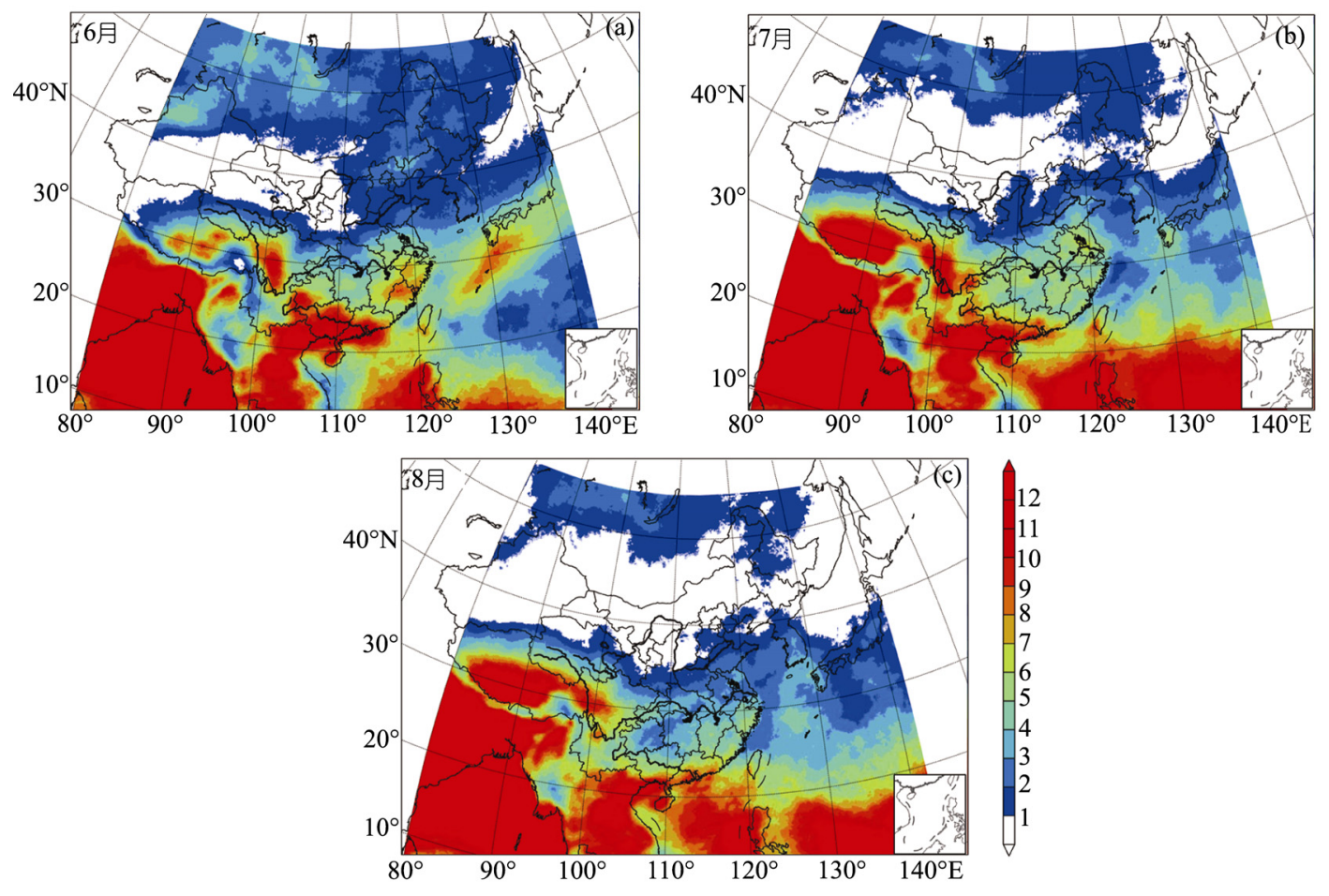

图 $36 \sim 8$ 月各个月 MCS 活动频率(单位: \%)

(a) 6 月; (b) 7 月; (c) 8 月

的活跃MCS在 7 和 8 月份比 6 月份更偏北, 这与 7,8 月份东亚夏季风向北推进、副高北跳相关 ${ }^{[22]}$. 两广地 区与云贵高原东北部的MCS活跃区 6 月份明显强于 7 和 8 月份, 但两广地区的月际变化不如云贵高原东北 部明显; 8 月份两广地区与云贵高原东北部的MCS分 布更偏南.

月际变化显著的区域还包括青藏高原中东部地 区、横断山区、川西高原、江淮地区、黄淮地区、浙 江与福建的武夷山区、琉球群岛与日本附近海域、新 疆西部的伊犁河谷地区、俄罗斯的萨彦岭到贝加尔湖 一带等.

在青藏高原的中部地区 6 月份 MCS 的发生频率 与分布范围明显弱于 7 和 8 月份; 横断山区、川西高 原与此不同, 8 月份明显弱于 6 和 7 月份; 长江以南的 浙江、福建、江西等地区以及琉球群岛附近海域的 $\mathrm{MCS}$ 活动 6 月份明显强于 7 和 8 月份; 但黄淮地区 的 MCS 活动 7 月份明显强于 6 和 8 月份.

对 $\mathrm{M}_{\alpha} \mathrm{CS}$ 分布的月变化(限于篇幅图未给出)分析 表明, 不同地区 $\mathrm{M}_{\alpha} \mathrm{CS}$ 分布的月变化与以上 MCS 分 布的月变化非常类似.
总结以上中国及其周边区域的MCS月变化特征 表明华南与华东的MCS分布明显受到东亚夏季风的 影响, 特别是黄淮地区. 7 月份季风气团最偏北 ${ }^{[22]}, 6$ 月份与 8 月份季风气团偏南, 相应的黄淮地区 7 月份 MCS分布明显偏北, 6 和 8 月份MCS分布偏南.

\section{$4 \mathrm{MCS}$ 日变化特征}

由于地球静止卫星红外云图具有 $1 \mathrm{~h}$ 一次的较高 时间分辨率, 因此可以根据这些资料对中国及周边 地区不同下垫面区域的 MCS 的日变化特征进行分析.

\section{1 区域日变化特征}

从中国及周边地区的整个区域的 MCS 日变化来看 (见图 4), 北京时间的上午时段 (00 04UTC)陆地区域的 MCS 活动频率最弱, 下午时段(06UTC)对流开始发展, 到傍晚时段(9 12UTC)MCS 活动达到最强盛时段, 凌 晨(18UTC)MCS 活动减弱. 特别在山区与沿海地区 MCS 这种日变化特征更为明显. 其中中国东部地区 09UTC MCS 最活跃, 青藏高原及其周边区域在 11UTC MCS 达到最活跃, 这实际是由经度差异(时差)造成的. 从当地时间来看都大约在下午 17 时 MCS 最活跃. 

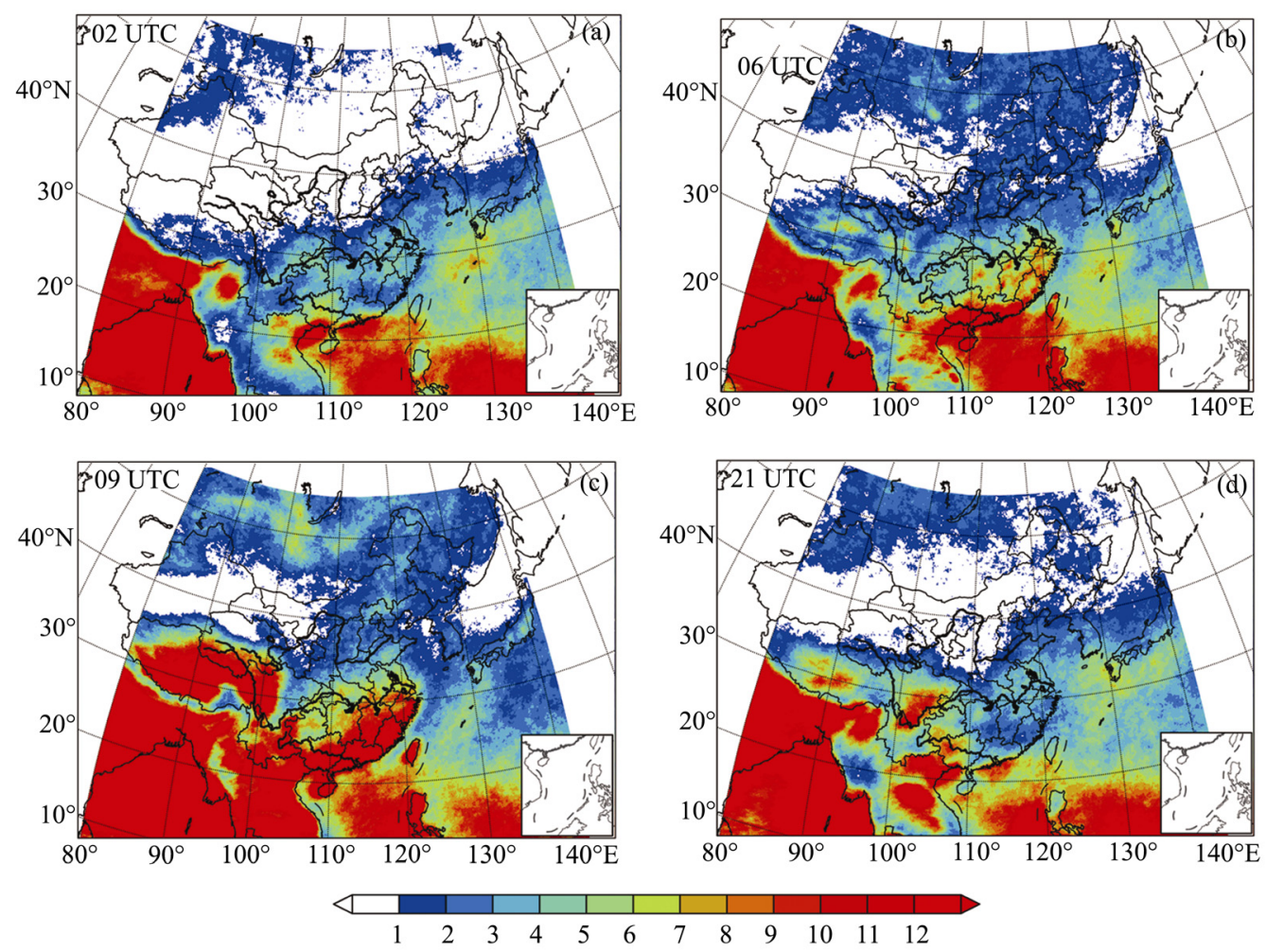

图 4 MCS 活动频率的日变化特征(单位: \%)

(a) 02UTC; (b) 06 UTC; (c) 09UTC; (d) 21 UTC

值得注意的是，有几个区域的日变化与以上日 变化特征不同. 第一个值得关注的区域是四川盆地. 该区域早晨到上午时段(20 06UTC)MCS 都较活跃, 从下午时段 MCS 活动减弱, 该区域的 MCS 具有明显 的夜发性.

第二个值得关注的区域是琉球群岛附近海域与 广东沿海附近海域. 这两个海区 MCS 活跃时段集中 在 20 09UTC，早晨、上午以及下午 MCS 活跃，傍晚 到午夜对流减弱(10 19UTC).

第三个需要关注的区域是广西与广东沿海地区. 该区域上午 03UTC MCS 开始发展, 到 08, 09UTC MCS 发展最旺盛, 17 02 UTC MCS 最不活跃.广西 与广东及其近海海域 MCS 日变化特征与该区域的海 陆风环流密切相关. 白天陆地区域受太阳短波辐射 加热空气上升、MCS 主要发生在陆地区域, 近海海域 MCS 不活跃; 日落之后陆地温度下降较快 MCS 活动 逐渐减弱、海洋 MCS 活动加强. 在海南岛以及台湾 岛的海岸线附近也具有类似的 MCS 日变化特征, 但 其特征不如广西与广东沿海地区的 MCS 日变化特征 明显.
在 4.2 与 4.3 部分将通过分析不同经线与纬线时 间剖面的方法来具体总结不同地区 MCS 日变化特征.

\section{2 沿不同经线 MCS 日变化特征}

为了考察不同下垫面区域 MCS 日变化特征，本 文分别给出 $90^{\circ} \mathrm{E}, 100^{\circ} \mathrm{E}, 110^{\circ} \mathrm{E}$ 和 $120^{\circ} \mathrm{E}$ 四条经线 $20^{\circ} \sim 50^{\circ} \mathrm{N}$ 范围内的 MCS 日变化特征(见图 5, 剖面位 置见图 1(a)的淡蓝色实线), 4.3 节将给出 $30^{\circ} \mathrm{N}$ 纬线 MCS 的日变化特征.

$90^{\circ} \mathrm{E}$ 经线所涵盖的区域为青藏高原南侧的孟加 拉国、印度与不丹以及我国的青藏高原、新疆等地区 (见图 1(a)). $90^{\circ} \mathrm{E}$ 经线上最突出的 $\mathrm{MCS}$ 日变化特征 (见图 5(a)) 是 $26^{\circ} \mathrm{N}$ 以南与印度季风涌相联系的活跃 $\mathrm{MCS}$ 与青藏高原上的强对流. $90^{\circ} \mathrm{E}$ 经线 $26^{\circ} \mathrm{N}$ 以南表 现为几乎全天任一时刻都有活跃的 MCS 发生发展, 这与我们日常对卫星云图的观察相一致. 青藏高原 MCS 虽然不如高原南侧活跃, 但其日变化特征明显 不同于我国其他地区(见图 5 和 6). 该经线上青藏高 原地区 MCS 日变化的特征主要包括以下 5 点：(i ) 对流起始时间早, 其起始时间为当地时间 12 时(06 UTC，即 14 BST); (ii ) 对流系统持续时间长，从 

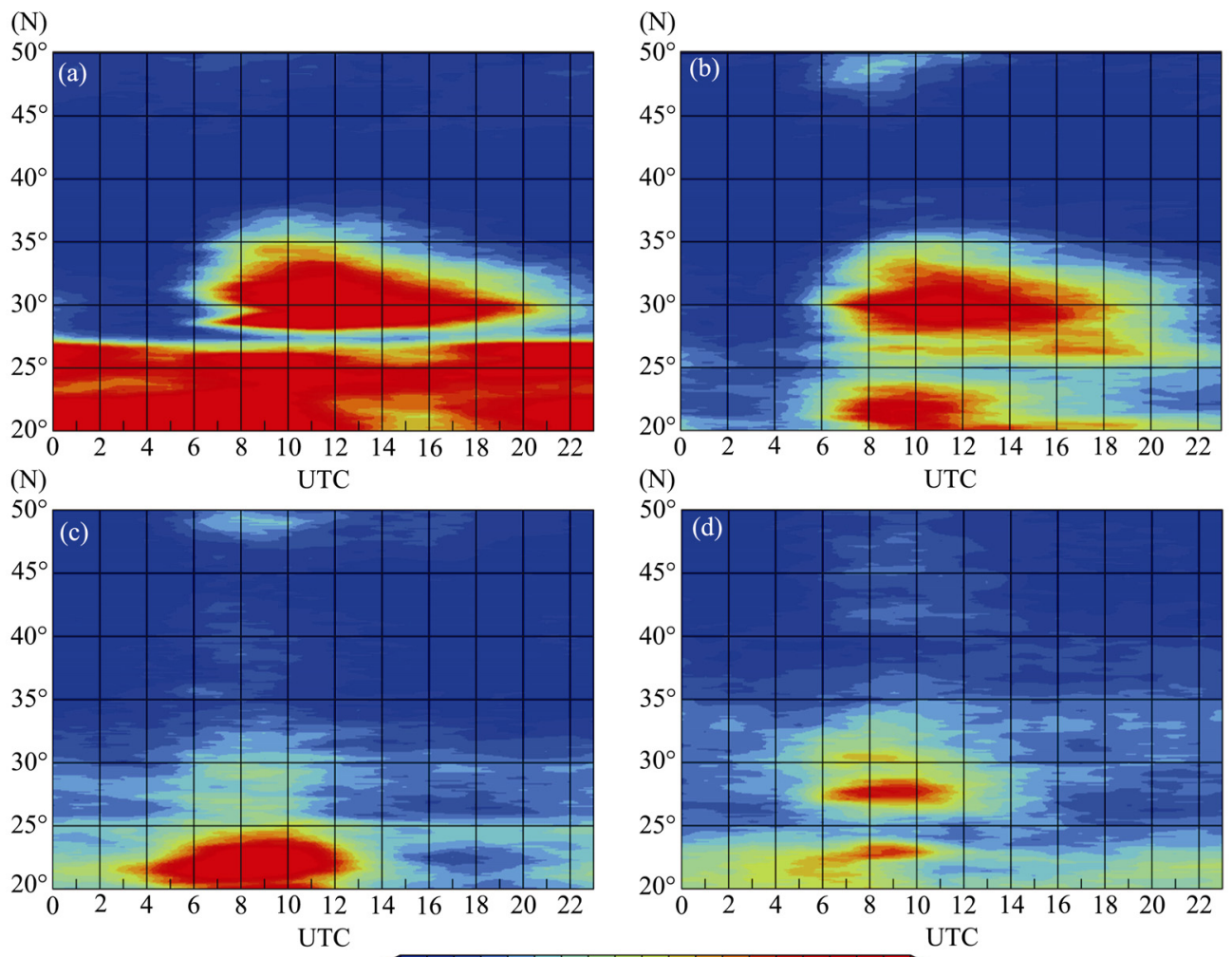

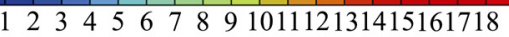

图 5 MCS 活动频率沿经线的时间-纬度剖面图(单位: \%, 横轴为时间, UTC, 纵轴为纬度) (a) $90^{\circ} \mathrm{E}$; (b) $100^{\circ} \mathrm{E}$; (c) $110^{\circ} \mathrm{E}$; (d) $120^{\circ} \mathrm{E}$

06UTC 持续到 21UTC，即从当地时间的中午持续到 凌晨 3 时; (iii) 青藏高原中南部对流时间持续时间长, 青藏高原北部对流时间持续时间短，与之对应 $90^{\circ} \mathrm{E}$ 青藏高原中南部有较多 $\mathrm{M}_{\alpha} \mathrm{CS}$ (见图 1(b)); (iv) 纬度 $31^{\circ} \mathrm{N}$ 以北 06-10UTC MCS 从南向北传播, 10 UTC 之 后 MCS 南撤, 青藏高原北部 MCS 活动逐渐减弱; (iv) 对流初始发展分别从 $28^{\circ} \mathrm{N}$ 与 $31^{\circ} \mathrm{N}$ 开始, 随着太阳短 波辐射的加强 $28^{\circ} \mathrm{N} \mathrm{MCS}$ 向北发展、 $31^{\circ} \mathrm{N} \mathrm{MCS}$ 向南 发展, 在 $30^{\circ} \mathrm{N}$ 附近 MCS 持续至 $21 \mathrm{UTC}$ 逐渐减弱.

$100^{\circ} \mathrm{E}$ 经线所涵盖的区域包括云南、横断山区、川 西高原、青海、甘肃、内蒙古西部、蒙古的杭爱山区 (见图 1(a)). 该经线上 MCS 日变化(见图 5(b))最突出 的特征是横断山区与川西高原的 MCS 非常活跃, 特 别是在 $27^{\circ} \mathrm{N}$ 云南西北部的横断山区 MCS 持续时间 长, 从 07UTC 持续到 $22 \mathrm{UTC}$, 与之相应的是有较多 $\mathrm{M}_{\alpha} \mathrm{CS}$ 发生发展(见图 1(b)). 川西高原的 MCS 日变化 特征类似于 $90^{\circ} \mathrm{E}$ 的青藏高原地区，也在 06UTC MCS 开始发展, 并在 06 11UTC MCS 向北传播发展, 在
12UTC 后 MCS 减弱南撤; 但是川西高原的 MCS 持 续时间明显短于 $90^{\circ} \mathrm{E}$ 青藏高原地区. 值得注意的是 $100^{\circ} \mathrm{E}$ 的云南地区 $\mathrm{MCS}$ 持续活跃时间明显短于川西 高原. 在北纬 $50^{\circ}$ 附近是 MCS 的第三个集中带, 但 MCS 持续时间比较短, 主要发生在 06-12UTC, 很少 $\mathrm{M}_{\alpha} \mathrm{CS}$ 发生发展(见图 1(b)), 并具有向东北方向传播 的特征.

$110^{\circ} \mathrm{E}$ 经过的区域为雷州半岛、广西东部、湖南 西部、湖北、陕西东部、内蒙古中部、蒙古中部等(见 图 1(a)). 该经线上的突出特征(见图 5(c)) 是雷州半 岛、广西东部的 MCS 比较活跃; 该区域 MCS 持续时 间长, 15 20UTC MCS 最不活跃, 具有上午发展的特 征; 此外, MCS 在 04 10UTC 向内陆发展, 10 14UTC 朝向海洋发展. 这种 MCS 的日变化特征与当地的海 陆风环流密切相关, 午后陆地温度高、陆地 MCS 活 跃，午夜后至上午时段海洋温度高、海洋 MCS 活跃.

$110^{\circ} \mathrm{E}$ 经线上 $\mathrm{MCS}$ 另一突出日变化特征为 $29^{\circ} \mathrm{N}$ 附近湖南平原地区呈现出多峰型特征, 这与 $\mathrm{MCC}$ (中 
尺度对流复合体)日变化 ${ }^{[11]}$ 以及北京的平原地区 $\mathrm{MCS}$ 日变化 ${ }^{[14]}$ 相似, 反映此类对流生命史较长, 水平尺度 也较大, 日落后曾一度减弱, 午夜时又再度发展, 它 可称为湿对流 ${ }^{[14]}$. 需要指出的是, 同图 1(b)相比较也 可以发现该区域是 $\mathrm{M}_{\alpha} \mathrm{CS}$ 活跃区域之一.

$120^{\circ} \mathrm{E}$ 经过的区域为巴士海峡、台湾西南部、台 湾海峡、浙江、江苏、山东半岛、渤海、辽宁西部、 内蒙古东部大兴安岭地区(见图 1(a)). 在该经线上巴 士海峡、台湾岛 $\left(20^{\circ} \sim 24^{\circ} \mathrm{N}\right.$ ) 附近的 $\mathrm{MCS}$ (见图 5(d)) 虽 然不如 $110^{\circ} \mathrm{E}$ 雷州半岛、广西东部区域活跃, 但日变 化特征与其有些类似, MCS 在傍晚至午夜时段 (11 16UTC)减弱. 该经线上MCS的另一突出特征是 $26^{\circ} \sim 31^{\circ} \mathrm{N}$ 的闽浙丘陵地带具有非常突出的单峰型日 变化特点 ${ }^{[14]}$, 与北京周边山区 $\mathrm{MCS}$ 的日变化特征类 似 ${ }^{[14]}$; 但需要指出的是由于该地区还是 $\mathrm{M}_{\alpha} \mathrm{CS}$ 的活跃 区域(见图 1(b)), 因此MCS也具有不太显著的夜发性 特征. 在该经线的 $33^{\circ} \sim 34^{\circ} \mathrm{N}$ 江淮平原地区的MCS日 变化特征呈现出多峰型特征, 与 $110^{\circ} \mathrm{E}$ 经线上 $29^{\circ} \mathrm{N}$ 附 近湖南平原地区以及北京的平原地区 $\mathrm{MCS}$ 日变化 ${ }^{[14]}$ 相似, 该区域同时也是 $\mathrm{M}_{\alpha} \mathrm{CS}$ 的活跃区域(见图 1(b)).

总结以上不同地区的MCS日变化特征可以发现这 里具有几种不同特征的MCS: 印度季风涌MCS、青藏 高原MCS、海陆交界MCS、一般山地热对流、多峰 型MCS. 印度季风涌MCS发生在青藏高原南麓的印 度、孟加拉国等地, 其特点是夏季几乎全天任一时次 都有活跃的MCS, 并且 $M_{\alpha}$ CS也非常活跃; 青藏高原 $\mathrm{MCS}$ 主要发生在青藏高原、横断山区与川西高原, 具 有午后开始发展、持续时间长的特点, 并且 $\mathrm{M}_{\alpha} \mathrm{CS}$ 比 较活跃; 海陆交界MCS以两广沿海最为典型, 具有午 后向陆地传播、午夜后向海洋传播的特征; 一般山地 热对流发生在山区与丘陵地带, 具有午后发展、持续 时间较短的特征; 多峰型MCS多发生在平原地区, 具 有类似于 $\mathrm{MCC}$ 日变化的特点, 它可称为湿对流 ${ }^{[14]}$; 多峰型MCS的发生区域也是 $\mathrm{M}_{\alpha} \mathrm{CS}$ 活跃区域之一.

\section{3 沿 $30^{\circ} \mathrm{N}$ 纬线 MCS 日变化特征}

北纬 $30^{\circ}$ 东经 $90^{\circ} \sim 130^{\circ}$ 涵盖了青藏高原中东部地 区、川西高原、长江中下游地区、我国的东海海域、 琉球群岛附近海域. 该纬度带的长江中下游地区是 我国梅雨锋暴雨多发的地区, 张顺利等 ${ }^{[24]}$ 发现青藏 高原地区MCS通过波动的形式影响长江中下游地区, 因此研究 $30^{\circ} \mathrm{N}$ 纬线上MCS日变化特征具有特殊的意 义.

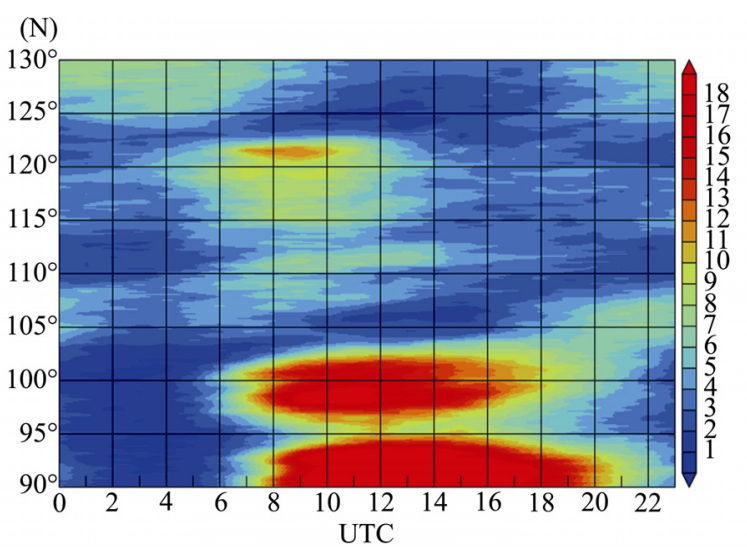

图 6 MCS 活动频率沿 $30^{\circ} \mathrm{N}$ 纬线的时间-经度剖面图 单位: \%, 横轴为时间, UTC, 纵轴为经度

同图 1(a)相对应, $30^{\circ} \mathrm{N}$ 纬线上 MCS 分布(见图 6) 的最突出特征是波动状分布的活跃 MCS 区, 并在 $100^{\circ} \sim 110^{\circ} \mathrm{E}$ (四川西部-湖北西部)与 $105^{\circ} \sim 113^{\circ} \mathrm{E}$ (四川 东部-湖北中部)具有向东传播的显著特点. 此外, 青 藏高原与川西高原 MCS 持续时间明显长于其他地区, 并且青藏高原 $\left(90 \sim 95^{\circ} \mathrm{E}\right)$ 的 $\mathrm{MCS}$ 持续时间长于川西高 原 $\left(96 \sim 104^{\circ} \mathrm{E}\right)$; 四川盆地 $\left(105^{\circ} \mathrm{E}\right)$ 与琉球群岛海域 $\left(125 \sim 130^{\circ} \mathrm{E}\right)$ 的对流具有明显的凌晨与上午活跃、傍晚 减弱特征. 四川盆地对流活跃时间大约在 18-08UTC, 不同于青藏高原与川西高原地区.

这种 MCS 活跃区分布除了与大气环流背景相关 外, 还明显与这些地区的下垫面性质、局地热力环流 相关. 首先, $30^{\circ} \mathrm{N}$ 纬线上高原与山地(青藏高原、川西 高原、闽浙丘陵等)对流旺盛, 盆地、平原、海洋(四 川盆地、长江中下游平原、琉球附近海域等) MCS 较 不活跃; 高原与山地 MCS 日变化呈现单峰型特征, 盆地与平原地区 $\mathrm{MCS}$ 日变化表现为多峰型特征. 其 次, $30^{\circ} \mathrm{N}$ 纬线上 $100^{\circ} \sim 110^{\circ} \mathrm{E}$ 从四川西部至湖北西部 18 23UTC MCS 的传播特征表明川西高原与盆地构 成的山谷风环流对该区域的 MCS 分布具有重要影响, 该局地环流使得下午-傍晚时段山区 MCS 活跃, 午夜 后(18 02UTC)盆地 MCS 活跃, 夜对流显著, 呈现出 显著的 MCS 向东传播特征. 第三, $105^{\circ} \sim 113^{\circ} \mathrm{E}$ 从四 川东部至湖北中部 00 14UTC MCS 也具有向东传播 的特征, 这和四川盆地与四川东部、重庆、湖北西部 的山区构成的山谷风环流有密切联系. 第四, 虽然 $120^{\circ} \sim 122^{\circ} \mathrm{E}$ 附近浙江丘陵地带的 MCS 在下午时段 (04 13UTC)活跃, 但该区域与其邻近的附近海域的 海陆风环流并未呈现出像四川附近 MCS 的向东传播 
的特征. 第五, 琉球附近海域的MCS日变化成因还不 太清楚. 但袁铁等人 ${ }^{[16]}$ 分析渤海、黄海和东海经常在 凌晨出现日最大闪电密度出现的原因是: 海水的热 容量大, 在白天因为海风的缘故, 下层空气可能比上 层冷, 气层反而稳定; 而夜晚海水释放大量的热量, 这 时下层空气又比上层暖, 气层变得不稳定.

总结沿 $30^{\circ} \mathrm{N}$ 纬线 MCS 日变化特征可以发现这 里的 MCS 除了包含 4.2 部分所提到的青藏高原 MCS、 一般山地热对流、多峰型 MCS, 还包括四川盆地夜对 流、琉球附近海域对流. 四川盆地夜对流的特点是持 续时间较琉球附近海域短, 主要集中在 18-02UTC; 琉球附近海域对流的特点是持续时间较长, 主要集 中在 20 09UTC. 值得注意的是, 四川盆地与琉球附 近海域 MCS 都具有夜发性的特点, 同时这两个区域 也是 $\mathrm{M}_{\alpha} \mathrm{CS}$ 活跃区.

总结本文 4.2 与 4.3 部分几种不同类型日变化特 点的 MCS 地理分布, 给出了如图 7 所示的概略图.

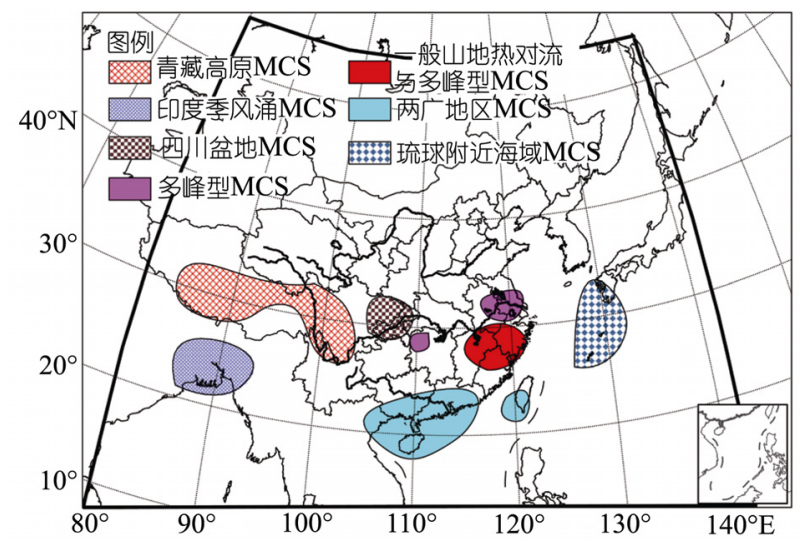

图 7 不同类型日变化特点的 MCS 分布概略图

\section{5 结论与讨论}

由于 10 年夏季静止卫星红外TBB资料具有较高 的时、空分辨率与很好的时、空完整性 ${ }^{[14]}$, 因此同已 有文献中使用地面观测资料进行雷暴统计 ${ }^{[1]}$ 与使用 低轨卫星观测的闪电资料分析结果 ${ }^{[15,16]}$ 进行比较可 以发现使用 TBB资料对 MCS的统计能够弥补使用其 他资料的不足, 并能够较全面地获得中国及其周边 地区MCS的分布特征及其日变化特点. 本文的统计 结果表明不仅不同的纬度地区的MCS分布特点不同，
区呈现为三条东西向带状分布, 并且 $30^{\circ} \mathrm{N}$ 附近MCS 的活跃中心表现为明显的东西向波动状分布; 这三 条MCS活跃带由东亚夏季风相互连结. 结合气候背 景分析 ${ }^{[22]}$ 表明热带季风气团(850 hPa假相当位温 $\geqslant$ 340 K)内MCS更活跃; 高原与山地(青藏高原、川西高 原、云贵高原、两广丘陵、南岭、闽浙丘陵、大兴安 岭等)对流相对活跃, 盆地、平原、海洋MCS相对较 不活跃; 不同下垫面MCS分布的月变化也不同. 因此, $\mathrm{MCS}$ 气候分布不仅与大尺度大气环流背景相关, 而 且与地形分布、海陆分布等导致的局地环流有着密切 的联系. 特别是不同下垫面区域MCS日变化气候分 布表明海、陆、山地热力差异引起的局地环流在很大 程度上决定了中国及周边地区夏季MCS活动的气候 特征.

对不同地区 MCS 日变化特征进行分析表明不同 地区 MCS 的日变化有所不同. MCS 的日变化特征可 区分为单峰型与多峰型, 单峰型 MCS 多发生在山区, 多峰型 MCS 多发生于平原与盆地. 对于单峰型 MCS 根据其持续时间与活跃时段的不同又可以区分为青 藏高原 MCS、一般山地热对流、琉球附近海域对流 等. 此外, 印度季风涌地区几乎全天 MCS 都很活跃; 四川盆地地区 MCS 夜发性特征显著; 两广地区海陆 交界处 $\mathrm{MCS}$ 具有午后向陆地传播、午夜后向海洋传 播的特征.

对比 $\mathrm{M}_{\alpha} \mathrm{CS}$ 分布与 $\mathrm{MCS}$ 日变化特征可以发现 MCS持续时间长(青藏高原、横断山区、川西高原等)、 夜发性 $\operatorname{MCS}$ (四川盆地、琉球附近海域)、多峰型 $\operatorname{MCS}$ (长江中下游平原地区) 活跃区域也是 $\mathrm{M}_{\alpha} \mathrm{CS}$ 的活 跃区, 这与 $\mathrm{M}_{\alpha} \mathrm{CS}$ 时间尺度较长、并且具有夜发性 ${ }^{[12]}$ 密切相关.

琉球附近海域 MCS 的日变化特征的成因还不是 特别清楚, 有必要从大气环流背景、黑潮对 MCS 的 影响等方面做进一步研究. 广东沿海附近与海陆风 相联系的 MCS 日变化特征突出, 但是在东海沿海并 未发现与海陆风密切联系的 MCS 日变化特征, 这可 能与琉球附近海域暖洋流导致的热力环流抑制了其 西侧东海沿海地区的海陆风环流有关, 不过这还需 要进一步的研究予以证实.

而且同纬度地区不同下垫面区域的 MCS 分布也不同.

从总体来看, 中国及其周边地区夏季MCS活跃 

供帮助, 中国遥感卫星数据服务网提供 FY2C 的 TBB 资料(网址: http://satellite.cma.gov.cn/), 在此一并致谢.

\section{参考文献} 2992[DOI] 165 1700-1706 306 600-608

张家诚, 林之光. 中国气候. 上海: 上海科学技术出版社, 1985. 411-436

Miller D, Fritsch J M. Mesoscale convective complexes in the western Pacific region. Mon Weather Rev, 1991, 119(12): 2978李玉兰，王婧熔，郑新江，等。我国西南-华南地区中尺度对流复合体(MCC)的研究. 大气科学, 1989, 13(4): 417-422

项续康，江吉喜. 我国南方地区的中尺度对流复合体. 应用气象学报, 1995, 6(11): 9-17

江吉喜, 项续康, 范梅珠. 青藏高原夏季中尺度强对流系统的时空分布. 应用气象学报, 1996, 7(4): 474-478

杨本相, 陶祖钰. 青藏高原东南部 MCC 的地域特点分析. 气象学报, 2005, 63(2): 236-242

Zheng Y G, Tao Z Y, Wang H Q, et al. Environment of meso- $\alpha$ scale convective system development in Yellow Sea region. Prog Nat Sci, 1999, 9(7): 842-848

郑永光，朱佩君，陈敏，等. 1993 1996 黄海及其周边地区 $\mathrm{M}_{\alpha} \mathrm{CS}$ 的普查分析. 北京大学学报(自然科学版), 2004, 40(1): 66一 72 段旭，张秀年，许美玲．云南及其周边地区中尺度对流系统时空分布特征．气象学报, 2004, 26(2): 243-249

费增坪，郑永光，王洪庆. 2003 年淮河大水期间 MCS 的普查分析. 气象, 2005, 31(12): 18-22

郑永光, 陈昫, 费增坪, 等. 2003 淮河流域持续暴雨的云系特征及环境条件. 北京大学学报(自然科学版), 2007, 43(2): 157-

Ma Y, Wang X, Tao Z Y. Geographic distribution and life cycle of mesoscale convective system in China and its vicinity. Prog Nat Sci, 1997, 7(6): 583-589

Anderson C J, Arritt R W. Mesoscale convective complexes and persistent elongated convective systems over the United States during 1992 and 1993. Mon Weather Rev, 1998, 126(3): 578-599[DOI]

郑永光, 陈昫, 陈明轩, 等. 北京及周边地区 5-8 月红外云图亮温的统计学特征及其天气学意义. 科学通报, 2007, 52(14):

马明, 陶善昌, 祝宝友, 等. 卫星观测的中国及周边地区闪电密度的气候分布. 中国科学 D 辑: 地球科学, 2004, 34(4): 298-

袁铁, 郄秀书. 卫星观测到的我国闪电活动的时空分布特征. 高原气象, 2004, 23(4): 488-494

Jirak I L, Cotton W R, Mcanelly R L. Satellite and radar survey of mesoscale convective system development. Mon Weather Rev, 2003, 131(10): 2428-2449 $\underline{\text { DOI] }}$

Maddox R A. Mesoscale convective complexes. Bull Amer Soc, 1980, 61(11): 1374-1387

Augustine J A, Howard K W. Mesoscale convective complexes over the United States during 1986 and 1987. Mon Weather Rev, 1991, 119(7): 1575-1589 [DOI]

Bluestein H B. Synoptic-dynamic Meteorology in Midlatitudes, Volume I, Principles of Kinematics and Dynamics. New York Oxford: Oxford University Press, 1992. 5-7

邹进上, 江静, 王梅华. 高空气候学. 北京: 气象出版社, 1990.296-299

郑永光, 张春喜, 陈昫, 等. 用 NCEP 资料分析华北暖季对流性天气的气候背景. 北京大学学报(自然科学版), 2007, 43(5):

郑永光, 陈昫, 葛国庆, 等. 梅雨锋的天气尺度研究综述及其天气学定义. 北京大学学报(自然科学版), 2008, 44(1); 157一164 张顺利, 陶诗言, 张庆云, 等. 长江中下游致洪暴雨的多尺度条件. 科学通报, 2002, 47(6): 467-473 